\title{
A PLANNING METHOD FOR ELECTRIC INFRASTRUCTURE TO SUPPLY MULTIMODAL TRANSPORTATION SYSTEMS
}

\author{
ANDRÉS E. DIEZ ${ }^{1}$, MELISSA RODRIGUEZ ${ }^{1}$, DANIEL A. ARROYAVE ${ }^{1}$, DIEGO A. MÚNERA ${ }^{1}$, \\ JOSE V. RESTREPO ${ }^{1}$ \& LUÍS E. CASTRILLON ${ }^{2}$ \\ ${ }^{1}$ Universidad Pontificia Bolivariana \\ ${ }^{2}$ Metro de Medellín, Colombia
}

\begin{abstract}
The paper presents a method to determine the proper infrastructure to supply electric energy for multimodal public transportation networks. The method integrates computational simulation tools in order to precisely calculate the power demand of each public transit system, and then, by accumulating the individual consumptions, obtain the global power system demand. The method is applied to the multimodal network operated by Metro de Medellin, which at the moment is experiencing an expansion.

Keywords: electric mobility, electrical demand, transport electrification, electric transportation modes, metro, tramway, cable car, trolleybus.
\end{abstract}

\section{INTRODUCTION}

Massive public transport systems that operate connected to an electric power grid will continue to be the core of transportation in large cities, as various research papers [1] [4] point. Electricity supply networks will be increasingly clean because of the incorporation of renewable energies and more intelligent allowing to optimize vehicle-vehicle and vehiclenetwork energy exchanges.

Despite the intensive work and research in developing grid-free vehicles using energy storage technologies, multimodal networks that combines different kind of electric vehicles and mobility alternatives represents an excellent opportunity to increase the offer of zero emission public transportation. Planning of the energy sources and distribution grids plus the selection of the different public transportation modes are one of the key areas where saving and efficiency strategies could be implemented.

As most of the transportations systems around the world have well established infrastructures, the improvements that can be achieved have a higher level of difficulty; while, on the other hand, underdeveloped countries have great constrains around infrastructure investments. Then, it is important to take account all the necessary incomes to develop a method that can improve the network construction and/or operation. Then, the method expected outcomes are: grid topology validation, capacity and specification of the power supply equipment such as transformers, rectifiers and feeders. The possible use of compensator systems, based on energy storage system or supply-re-injection technologies such as reversible substations, is considered.

The second section explains the first stage of the proposed method, consisting of the description and characterization of each single electric mode operated by Metro de Medellin. The third section presents the results of the application of the method to the expansion of the multimodal network operated by Metro de Medellin. The final section contains the conclusions, recommendations and further work. 


\section{PLANNING METHOD}

Currently Metro's multimodal-network is constituted by two heavy railway lines, Line A and Line B $(34 \mathrm{~km})$, four cable car branches $(10.7 \mathrm{~km}$ in total), and a tramway line $(4.2 \mathrm{~km})$. .1 shows pictures of the main components of the system (Fig. 1). One new cable car branch, connected to the tramway, is under construction. Another cable car line will be added in 2017, and a new tramway line through the "Carrera 80 (80th avenue)" and another cable car are foreseen. Electrical traction predominates in the system. Fig. 2 presents the basic typology of the network (Fig. 2).

The Metro network registers about one million trips per day, which represents approximately $13 \%$ of the total trips of the city. The only non-electric mode operated by Metro de Medellin is the Bus Rapid Transit (BRT) lines, currently used by almost 180,000 passengers in a daily basis. The buses use compressed natural gas, but future electrification using modern trolleybuses [5], [6], is under study.

Excluding the Metro network, trips in the city are $26 \%$ made by pedestrians, $28 \%$ in buses, $10 \%$ in taxi, and $5 \%$ by bicycle, and other means. However, the share of personal transportation in cars and motorcycles remains high, representing $25 \%$ of all trips. Consolidation of the multimodal network is a key strategy to move a number of commuters to clean public transport systems. This is key for the city as for air quality, a growing concern, because for the first time an environmental emergency was declared. It was caused by peak levels of concentrations of Particulate Matter (PM2.5 and PM10), mostly (about 60\%) coming from vehicles using combustion engines.

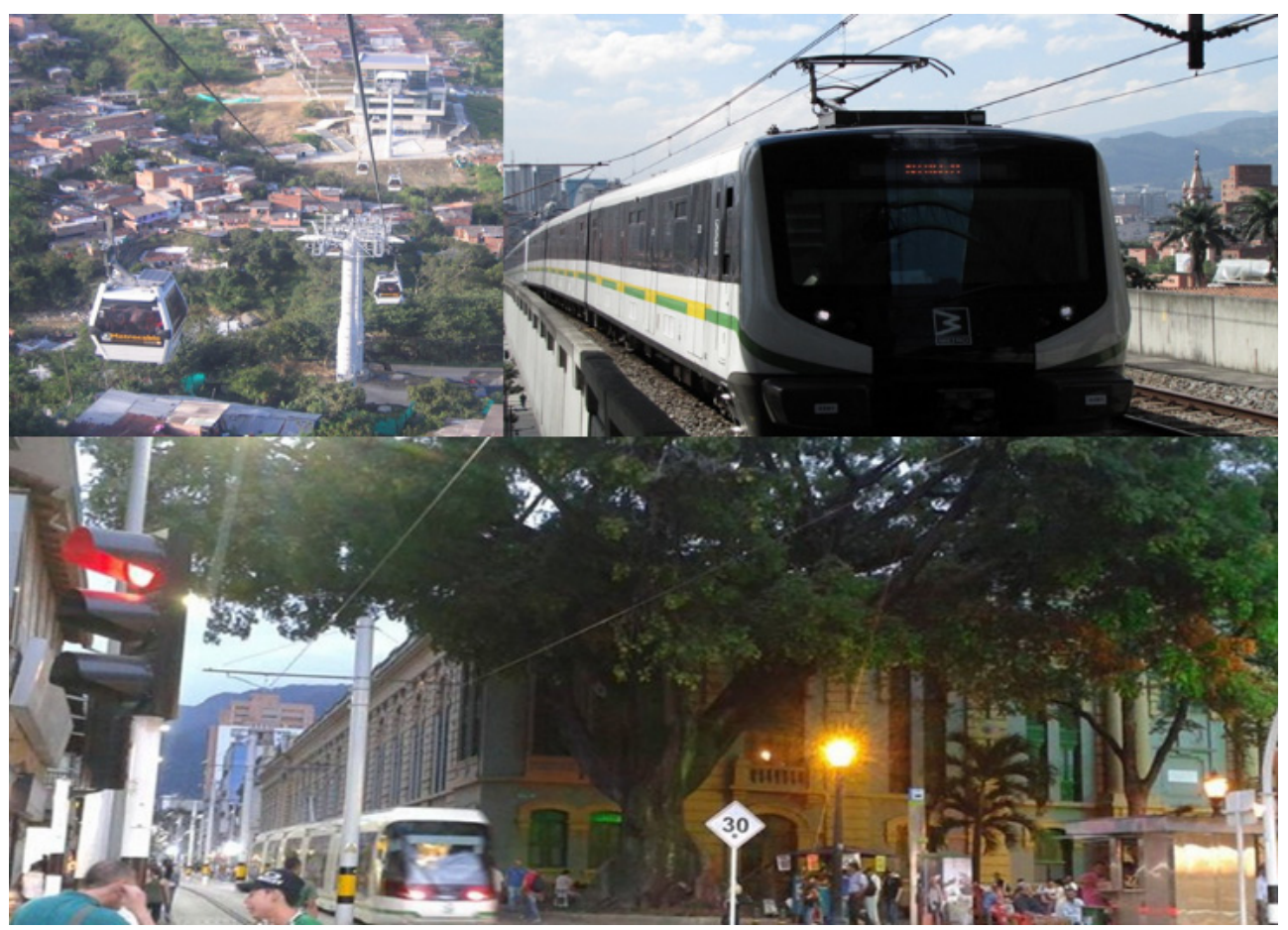

Figure 1: Upper left, Cable Car "Metrocable", upper right heavy train Line A, bottom, Ayacucho Tram Line. (Source: Own.) 


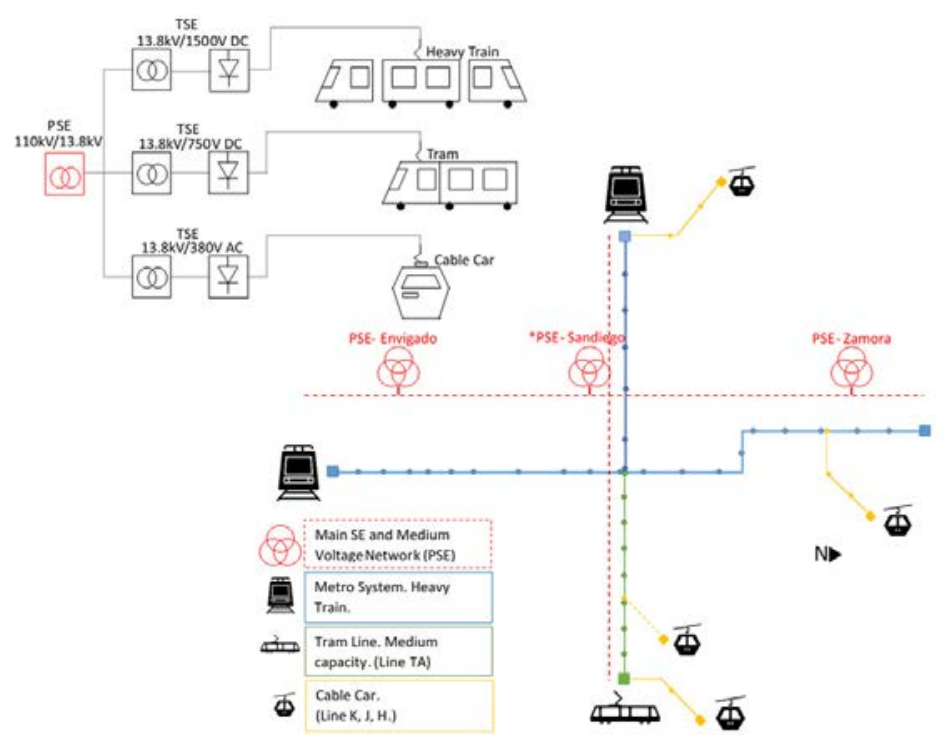

Figure 2: Multimodal system, operated by the company Metro of Medellin. (Source: Own.)

\subsection{Individual energy demand characterization by commute mode}

\subsubsection{Heavy train}

From an electric point of view, a train is a very good example of a load with variable demand. An accelerating train requires a high-power demand to rapidly overcome the high inertia, the static friction and eventually gradient forces. And when the vehicle brakes, power flow could be reverted due to regenerative braking. Obtaining the power demand from a traction substation by analytical methods is difficult because it depends on many factors (such us the amount of trains, scheduling, distant between stations, route profile and other physical characteristics), but nowadays computer simulation eases the task. There are several computer tools to simulate almost every aspect of railway operational and energetic features. Although some undergraduate students develop their own railway simulation algorithms, when the network complexity increases and there are precision requirements, usage of commercial software is a better option for network operators.

Since its initial operation, the power supply of Metro de Medellin consists of three main substations with a capacity of 40 MVA each, interconnected to build a medium voltage network $(13.8 \mathrm{kV})$. Each substation contains a transformer that marks the frontier with the national interconnection system, which work at the $110 \mathrm{kV}$ level. These substations are placed along the main line (Line A) of Metro de Medellin, from south to north, and are designated: Envigado, San Diego and Zamora (Fig. 2). Metro de Medellin owns the medium voltage network and the transformers of the main substations.

In 1995, when the system began commercial operation, the electric network allowed the circulation of 35 trains, which carried 200.000 passengers per day. Today, the same network holds the operation of 70 trains, 14 trams and four Cable Cars (Metrocable) systems (Fig. 1). This operational growth was possible by only increasing the calibre of two feeder lines in the medium voltage network without a major investment in equipment replacement, a sign of good planning practices. 
Connected to the medium voltage network, there were nine traction substations initially. A new (number ten) traction substation was added when the system was expanded $2.5 \mathrm{~km}$ to the south in 2012. They all feed current to the overhead 1500 VDC line to power the heavy trains. The average spacing between traction substations is $3.5 \mathrm{~km}$, and under normal operating conditions, they are evenly distributed among the three main feeders. The capacity of each traction substation is 7.6 MVA, conformed by two symmetrical rectifier groups of 3.8 MVA. Two special substations have three rectifier groups, for a total traction capacity of 83.6 MVA. The ratio between installed power capacity (120 MVA), compared to installed capacity for traction (83.6 MVA), is 1.43 , which is justifiable by the reliability criteria (n-1). In the case of the study presented in this paper, the power demand of the three traction substations, that operate in Line B, along with the three (currently two in operation) traction substations of Ayacucho tram and the two traction substations of the cable cars, which are all connected to San Diego main substation, is assessed.

Using measurements, the power demand of the two heavy rail lines is characterized by using the classic indexes. Table 1 present, as an example, the parameters of aggregated demand of the three traction substation of Line B in Metro de Medellin.

The load profile of a one traction substation is presented in (Fig. 3). It is possible to clearly identify the peak traffic hours during the morning and in the afternoon, and the light traffic period between them.

Table 1: Aggregated load of train mode. (Source Own.)

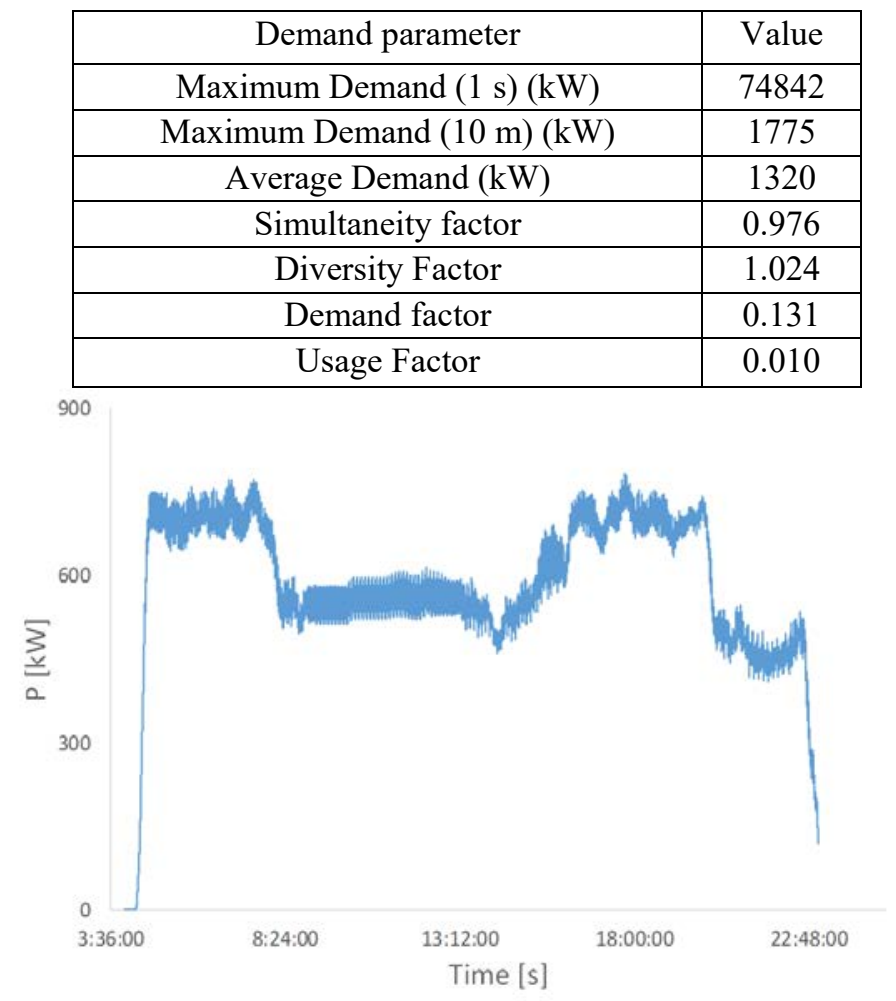

Figure 3: Traction substation daily power demand, Metro System, Line B. (Source: Own.) 


\subsubsection{Tram}

In 2015, the Ayacucho tramway (Line TA) began commercial operation in a route of $4.3 \mathrm{~km}$ in length with 12 vehicles, each with a capacity of 300 passengers. It is expected that 80,000 trips are made on a daily basis. After an assessment of energy consumption and power demand, it was decided to feed the Ayacucho tramway from the existing medium voltage network, specifically, from San Diego Substation, because it is near to the project. To release load from San Diego substation, two traction substations of Line A were reconfigured to be feed under normal operation, one from Envigado and the other one from Zamora.

The power system capacity estimated by the contractor in the initial design accounted a total of 5.4 MVA, distributed in three traction substations of 1.8 MVA. However, a constructive problem in a building that would contain one of the substations render impossible to have it fully operational at the expected inaugural date. Then, it was decided to start commercial operation using only seven tram units at peak hours, with the system only powered from the two available substations, which are located at both ends of the route.

The operation was favoured by the initial low demand of the system, which in the first months did not surpass 20,000 users per day. One year after inauguration, trips have reached 32,000 per day, with the inflow of new users thanks to the operation of one of the Metrocable systems, line H. In the current panorama is the need to increase the fleet and the concern of not having the third substation available yet. As a consequence, detailed simulation has been key for decide the gradual incorporation of new units. A satisfying unexpected result emerged: due to the high gradient of the line, the more trams operating, the more is the energy interchanges among trains ascending and descending, through regenerative braking. This natural compensation reduced peak demand of the traction substation near to the gradient (Oriente substation) by $10 \%$ when the fleet was increased from seven vehicles to twelve. The average gradient of Ayacucho Tramway is $5 \%$; the maximum gradient is $12 \%$. Operation is possible because the vehicles use tires for traction instead of train wheels. Table 2 presents the aggregated demand parameters of the two substation of Ayacucho Tram line and the Fig. 4 shows the daily load profile of a substation of Ayacucho tram (Fig. 4).

Table 2: Aggregated load of tram mode.

\begin{tabular}{|c|c|}
\hline Demand parameter & Value \\
\hline Maximum Demand (1 s) (kW) & 2500 \\
\hline Maximum Demand (10 m) (kW) & 1403 \\
\hline Average Demand (kW) & 989 \\
\hline Simultaneity factor & 0.998 \\
\hline Diversity Factor & 1.001 \\
\hline Demand factor & 0.189 \\
\hline Usage Factor & 0.200 \\
\hline
\end{tabular}




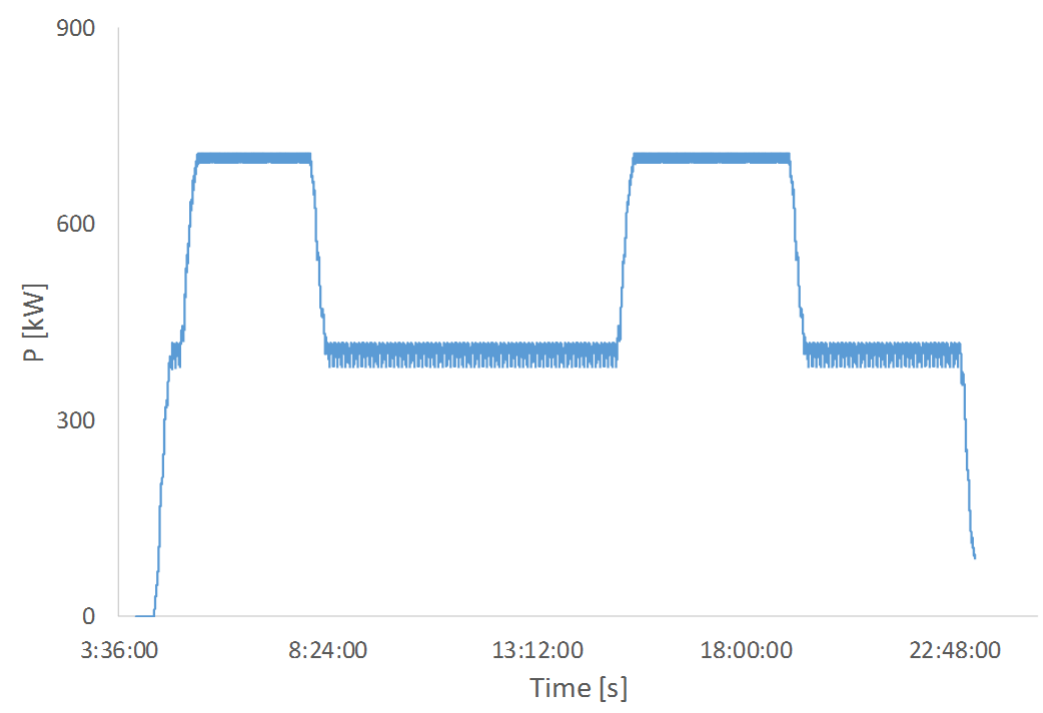

Figure 4: Traction substation daily demand, Line TA. (Source: Own.)

\subsubsection{Cable car}

In 2004, the first Metrocable system, called the K-line, was added with a capacity of 3000 passengers per hour per direction (pphs). This system allowed the transformation of depressed neighbourhoods in the north-eastern commune, along a corridor of $2.07 \mathrm{~km}$, with great results in mobility, safety and positive social impact that has been measured in several studies [7]-[10].

After a power demand assessment, the planners decided to feed the K-line from the medium voltage network of the company, using one of the feeders in the traction substation Acevedo supplied by main substation Zamora. This line constituted the first transport mode, different to trains, to be connected to the medium voltage network of Metro de Medellin.

The cable car lines are pulled by only one traction motor. The power demand is very constant only changing with passenger load. In the morning people descend from the hilly neighbourhoods to work at downtown, and the energy consumed by the system is for braking, due to decompensation caused by cabins ascending with low weight, and those descending full of people. Unfortunately, the regenerative braking energy of the cables is currently dissipated in resistors, but it could be either stored or returned to the AC network by connecting a reversible substation or a compensation system based of energy storage devices like ultra-capacitors or batteries.

The case presented in this paper will consider two similar cable car systems connected to the tram line, and fed by the main substation San Diego. The data presented in Table 3 corresponds to measurements made in Line $\mathrm{H}$, which is under load test before inauguration. These were multiplied by two to incorporate the future new cable car, Line M. In this paper, the demand of the other cable car system, Line M, will be considered equal to Line H. But once measurements of the new line become available, the data has to be adjusted. 
Table 3: Aggregated demand of cable car mode.

\begin{tabular}{|c|c|}
\hline Demand parameter & Value \\
\hline Maximum Demand $(\mathrm{kW})$ & 500 \\
\hline Average Demand $(\mathrm{kW})$ & 288 \\
\hline Simultaneity factor & 1 \\
\hline Diversity Factor & 1 \\
\hline Demand factor & 0.575 \\
\hline Usage Factor & 0.833 \\
\hline
\end{tabular}

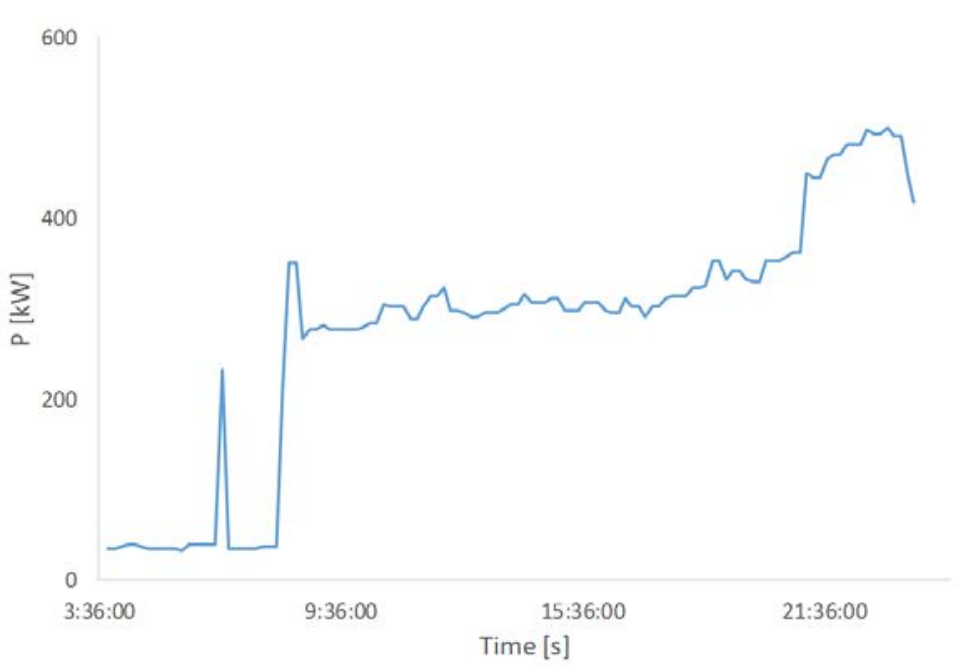

Figure 5: Traction substation daily demand, cable car system. (Source: Own.)

The load profile of the substation (Fig. 5) shows the daily load profile of a Cable Car Line.

Compared with train and tram load profiles, the cable car demand remains relatively constant, until afternoon when people return home and the load of the cars that ascend is higher than those descending. In addition, no great voltage fluctuations are register as seen on the train and tram modes.

\subsection{Demand aggregation method}

A method is required to aggregate individual demand by mode to get the overall load profile in the node considering that different modes are feed from the same electrical node, and this situation will be common in new projects. Currently, coupled in a common point are four traction substations of the main Metro line, the three substations of Ayacucho's tramway, and the two substations of the cable car lines. To perform the aggregation, the load demand data of each mode is added, second by second, using a power flow simulator, to take into account the topology and electric parameters of the grid. Fig. 6, presents the daily load profile from the Metro, the tramway, the cables, and the aggregated demand profile (Fig. 6). 


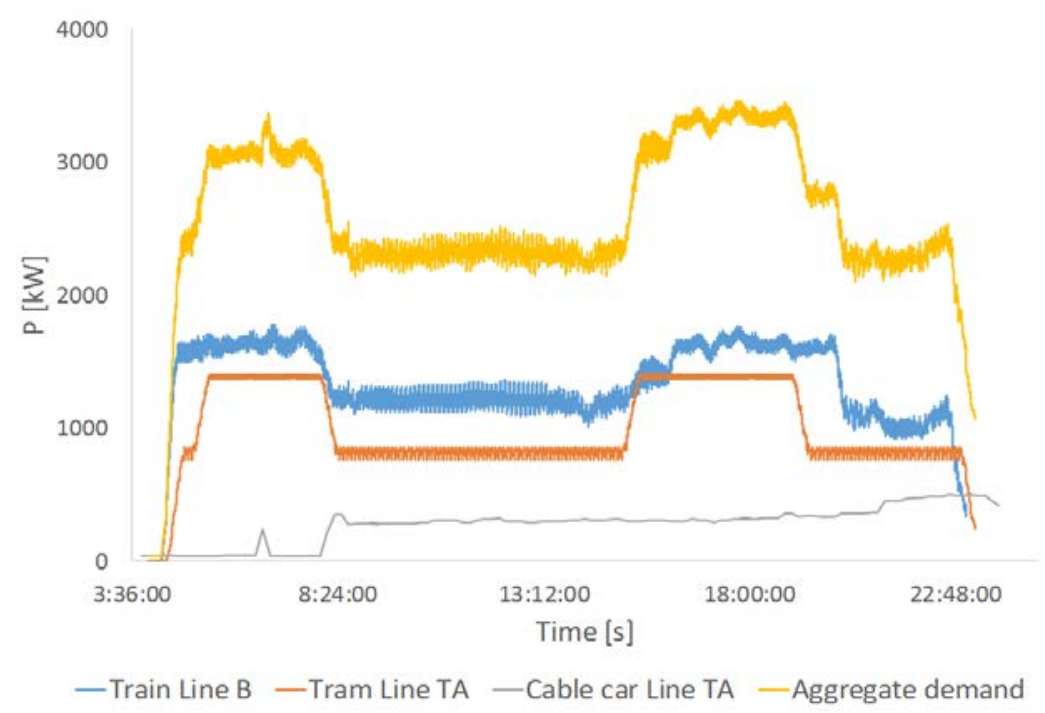

Figure 6: Overall multimodal demand in San Diego. (Source: Own.)

Table 4: Overall aggregated demand.

\begin{tabular}{|c|c|}
\hline Demand parameter & Value \\
\hline Maximum Demand (1 s) $(\mathrm{kW})$ & 9275 \\
\hline Maximum Demand (10 m) $(\mathrm{kW})$ & 3465 \\
\hline Average Demand (10 m) $(\mathrm{kW})$ & 2567 \\
\hline Simultaneity factor & 0.942 \\
\hline Diversity Factor & 1.062 \\
\hline Demand factor & 0.155 \\
\hline Usage Factor & 0.099 \\
\hline
\end{tabular}

Table 4 presents the results of the aggregated demand of all modes.

The operating limits for traction substations are based on the applicable design standard [8], which for the case of Metro de Medellin train lines and Ayacucho tramway is Class Service VI defined for main railroad applications, mass transit and light rail systems. The Class Service IV class requires the system to support a load of $300 \%$ (nominal capacity) for one minute, $150 \%$ for two hours periods and nominal load continuously. For the case of 
aggregate demand in periods of 10 minutes, the $150 \%$ limit is applied. The short duration power requirements (less than $1 \mathrm{~min}$ ) were verified with the limit of $300 \%$ in capacity, individually for each converter, using simulation tools.

The definition of the policies should also consider the conditions of reliability and availability of the electrical infrastructure network in case of failure of one of the Electric Power Substations (SE), without degrading the operation and the provision of the service. This is known as system capacity enabled to operate with n- 1 conditions. The power overload limit is determined by the power transformer technology, which in this case is oil, and must meet the requirements of IEC standards [10]. According to this standard, the power transformer is designed to withstand an overload of $50 \%$ permanently. Voltage levels have to fulfil the requirement of the standard about Railways applications [11], and the medium voltage network have to fulfil the requirements of the local Power Quality regulation [12]. Most important limits are: Total Harmonic Distortion of the voltage (THDv) set to $5 \%$, the individual voltage harmonics to $3 \%$, the short-Term Flicker perception (Pst) to 1.0, steady state voltages between 0.9 and 1.1 p.u. Power Quality limits have to be fulfilled the $95 \%$ of the time in a weekly basis.

\section{SOFTWARE INTEGRATION AND APPLICATION CASE}

With all the characteristics of each transportation mode, the integration and analysis process can start. First, thanks to the possibility to generate detailed aggregate demand curves using simulation software, projected demand curves can be generated for new scenarios as new fleet or new modes of transportation can be incorporated into the system. These curves were previously validated by comparing the simulation of real operational cases with direct measurements to the system. The software used for this process are known as OpenPowerNet ${ }^{\circledR}$ and OpenTrack ${ }^{\circledR}$.

Then, an application was developed to integrate the information generated by the rail simulation program, and obtain the overall system demand. This data comes from each mode, taking into account the overall scenario of the system and the specific characteristics of each mean of transportation. This data is consolidated keeping a one-second resolution. In other words, the application takes the one-second demand data, previously generated by the OpenPowerNet ${ }^{\circledR}$ simulation tool, and consolidates it as entry data for the next simulation tool.

Later, the resulting overall data is inserted into a power system analysis software, known as DIgSilent ${ }^{\mathbb{B}}$. It that can execute the simulation of hundreds of power flows in the AC medium-voltage grid for each scenario. With the second tool, second by second power flows are tested to assess the load of all branches, wires and substations of the medium-voltage network. The one-second voltage levels in the key nodes of the network are verified to be among the standard recommendations, along with harmonic distortion limits. The results obtained after applying the aggregation method, are also validated by comparing them with measurements in the medium voltage network.

To illustrate the importance of the last process, simulations with future scenarios for the whole system (Line A, Line B, Tram, Cables, etc.) where performed. The new conditions for this scenario are the increase in the fleet of high capacity trains, which goes from 50 units to 70 , and/or the increase in the number of trams, which goes from seven to twelve vehicles.

The final result shows the utilization factor of the three main power substations (Zamora, San Diego, Envigado) in the future scenario described (Fig. 8). The procedure to aggregate the demands of the modes is described below (Fig. 7). 


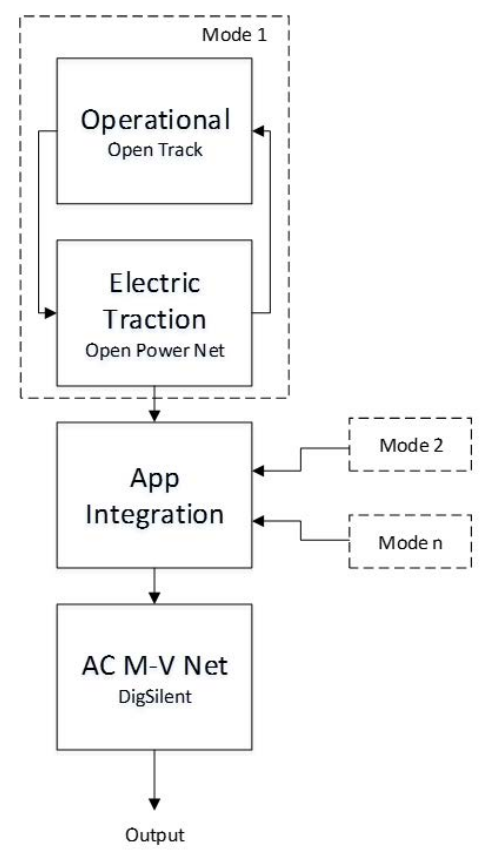

Figure 7: Procedure of integration of simulation tools. (Source: Own.)

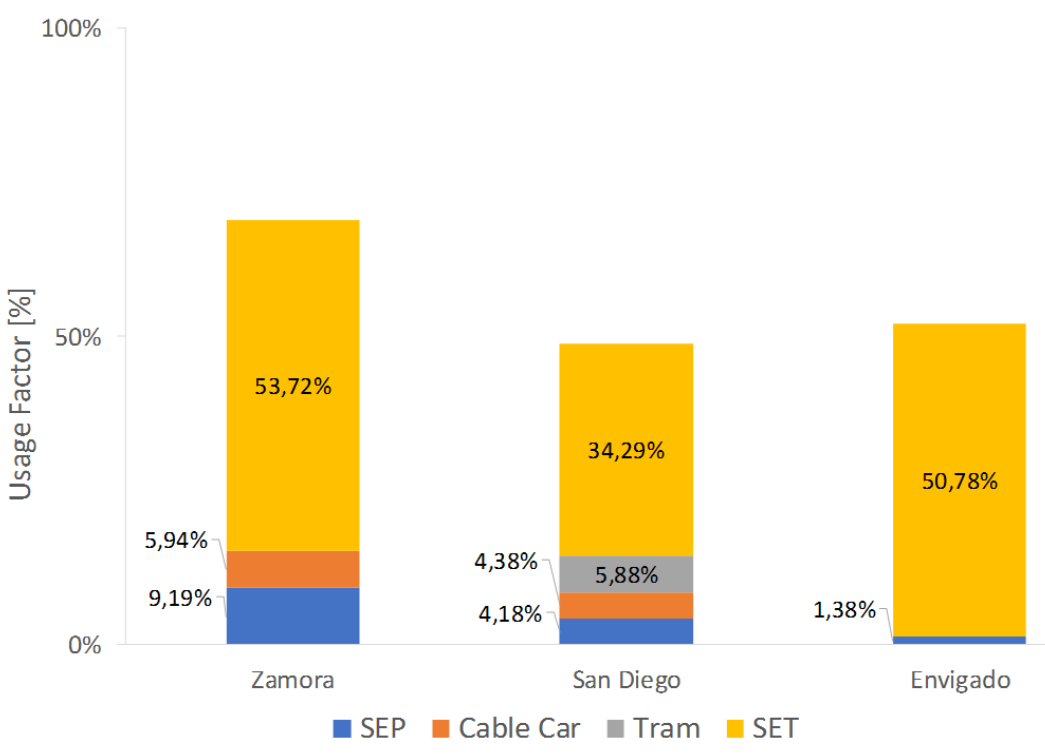

Figure 8: Usage factor (10 min peak) of main substations and mode share of the demand. (Source: Own.) 
The composition of the projected consumption demand, discriminated by train mode -SET-, Metrocables -Cables-, passenger stations -SEP-, and the Tram, is obtained. As an example, the maximum 10 minutes peak power is presented in the paper (Fig. 8). This is a fundamental input for the future planning and management of the electric infrastructure. Results show that new means of transportation, such as a new tram line and/or the electrification of existing BRT system, if using the existing infrastructure would have a significantly lower capital cost.

The system is also tested under $\mathrm{n}-1$ condition at main substation, $\mathrm{n}-1$ condition in traction substation, and a combination (very unlikely) of both contingencies. When the operative condition implies voltages outages of the standard limits, compensation systems are considered [14].

\section{CONCLUSIONS}

As urban multimodal electric mobility is fundamental to sustainable cities, this work attempts to contribute generating arguments, methods and software applications to ease decision making related to electric infrastructure investments, one of the most important barriers of the electrification of public transportation systems.

The proposed methodology is expected to give the necessary information about the demand of the multimodal system operated by Metro de Medellin (or any other operator) to support planning of the electrical infrastructure to feed the network. The methodology will help to identify the necessary investments at the appropriate moments, improving the costbenefit relationship of the projects needed to expand the multimodal network.

As further work, the application software to integrate railway with power simulation tools should incorporate automatic optimization algorithms, to find best solution alternatives to infrastructure projects. The potential for increasing the supply of electric transport in the city is great, and even the night-time use of existing infrastructure, to charge battery operated buses, taxis and bicycles should be contemplated.

\section{ACKNOWLEDGEMENT}

The support is grateful to Ruta $\mathrm{N}$ and to the company Metro de Medellin to the project "Modelo para el Planeamiento Estratégico del Sistema de Alimentación para las Redes Multimodales de Transporte Eléctrico Aplicado al Metro de Medellín".

\section{REFERENCES}

[1] Gilbert, R. \& Perl, A., Grid-connected vehicles as the core of future land-based transport systems. Energy Policy, 35(5), 3053-3060, (2007).

[2] Gilbert, R. \& Perl, A., Transport revolutions: moving people and freight without oil. New Society Publishers, 2013.

[3] Dallinger, D., Gerda, S. \& Wietschel, M., Integration of intermittent renewable power supply using grid-connected vehicles-A 2030 case study for California and Germany. Applied Energy, 104, 666-682, 2013.

[4] Haghbin, S., Lundmark, S., Alakula, M. \& Carlson, O., Grid-connected integrated battery chargers in vehicle applications: Review and new solution. IEEE Transactions on Industrial Electronics, 60(2), 459-473, 2013.

[5] Diez, A. et al., "Modern trolleybuses on Bus Rapid Transit: Key for electrification of public transportation". ANDESCON. IEEE. Bogota. 2010.

[6] Diez, A. et al., "The reintroduction of grid-connected alternatives into the planning of mass transportation systems in Colombia”. In: Energy and Sustainability VI. 2015 
[7] Cordoba, D. Z., Stanley, J. \& Stanley, J. R. (2014). Reducing Social Exclusion in Highly Disadvantaged Districts in Medellín, Colombia, through the Provision of a Cable-Car. Social Inclusion, 2(4).

[8] Brand, P. \& Dávila, J. D., Mobility innovation at the urban margins: Medellín's Metrocables. City, 15(6), 647-661, (2011).

[9] Heinrichs, D. \& Bernet, J. S., Public Transport and Accessibility in Informal Settlements: Aerial Cable Cars in Medellín, Colombia. Transportation research procedia, 4, 55-67, 2014.

[10] Railway applications - Fixed installations - Electronic power converters for substations, CSN EN 50328, 2003.

[11] Power transformers - Part 7: Loading guide for oil-immersed power transformers, IEC 60076-7, 2005.

[12] Railway applications - Supply voltages of traction systems, IEC 60850, 2014.

[13] Resolución N 065 de 2012, Comisión de Regulación de Energía y Gas. 2012.

[14] Díez, A.E., Alzate, P., Restrepo, J.V., Castrillon, L., Manrique, E. \& Figueroa, M., "DC compensation systems and their implications on the planning of expansions in Metro systems: a case study of Medellin," WIT Trans. Ecol. Environ., vol. 195, pp. 281-291, 2015. 